Conf $950256--1$

UCRL-JC-117918

PREPRINT

\title{
A Hybrid Vehicle Evaluation Code and Its Application to Vehicle Design
}

\author{
Salvador M. Aceves \\ and
}

J. Ray Smith

This paper was prepared for submittal to 1995 SAE International Congress and Exposition

Detroit, MI

February 27 - March 2, 1995

July 15, 1994

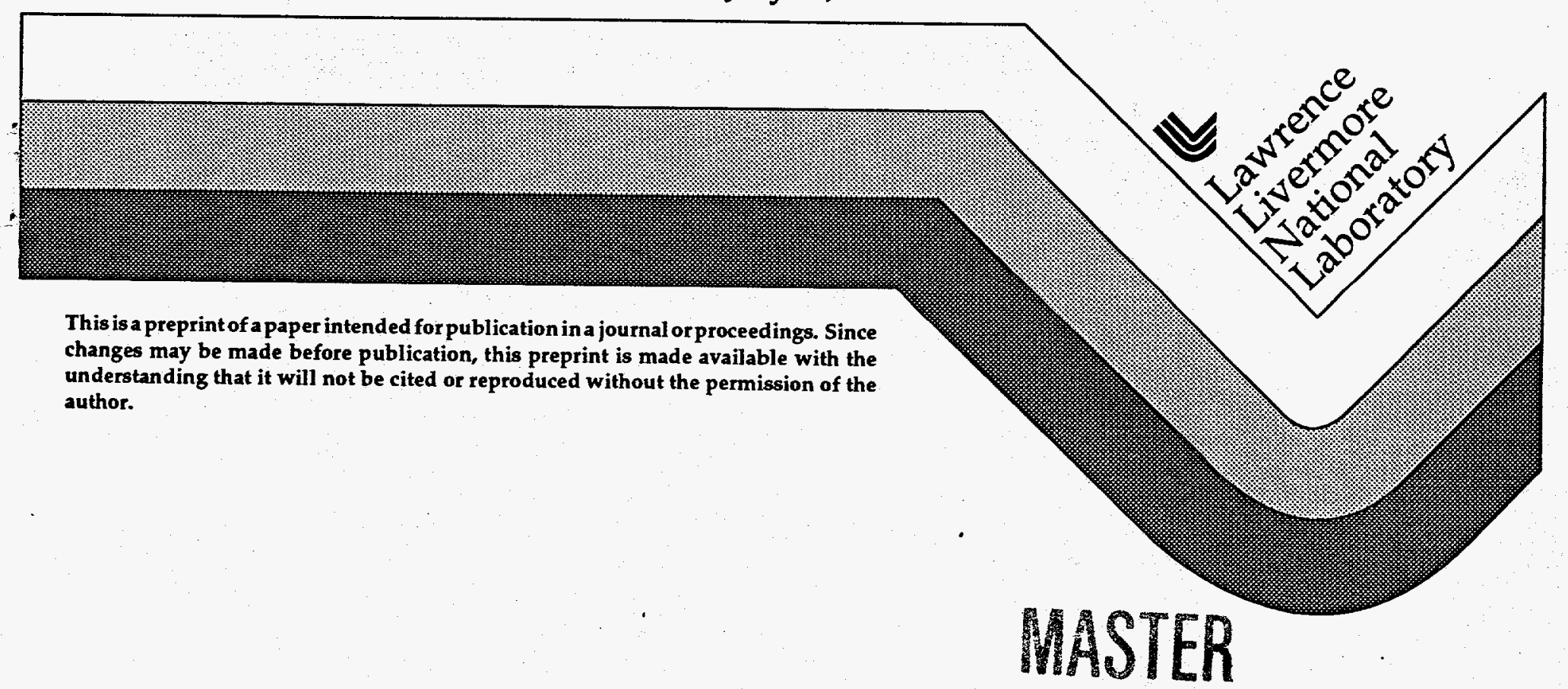




\title{
A HYBRID VEHICLE EVALUATION CODE AND ITS APPLICATION TO VEHICLE DESIGN*
}

\author{
by \\ Salvador M. Aceves and J. Ray Smith \\ Lawrence-Livermore National Laboratory \\ Livermore, CA 94550
}

\begin{abstract}
This report describes a hybrid vehicle simulation model, which can be applied to many of the vehicles currently being considered for low pollution and high fuel economy. The code operates interactively, with all the vehicle information stored in data files. The code calculates fuel economy for three driving schedules, time for $0-96 \mathrm{~km} / \mathrm{h}$ at maximum acceleration, hill climbing performance, power train dimensions, and pollution generation rates.
\end{abstract}

This report also documents the application of the code to a hybrid vehicle that operates with a hydrogen internal combustion engine. The simulation model is used for parametric studies of the vehicle. The results show the fuel economy of the vehicle as a function of vehicle mass, aerodynamic drag, engine-generator efficiency, flywheel efficiency, and flywheel energy and power capacities.

*This work performed under the auspices of the U.S. Department of Energy by the Lawrence Livermore National Laboratory under Contract No. W-7405-ENG-48. 


\section{DISCLAIMER}

This report was prepared as an account of work sponsored by an agency of the United States Government. Neither the United States Government nor any agency thereof, nor any of their employees, make any warranty, express or implied, or assumes any legal liability or responsibility for the accuracy, completeness, or usefulness of any information, apparatus, product, or process disclosed, or represents that its use would not infringe privately owned rights. Reference herein to any specific commercial product, process, or service by trade name, trademark, manufacturer, or otherwise does not necessarily constitute or imply its endorsement, recommendation, or favoring by the United States Government or any agency thereof. The views and opinions of authors expressed herein do not necessarily state or reflect those of the United States Government or any agency thereof. 


\section{DISCLAIMER}

Portions of this document may be illegible in electronic image products. Images are produced from the best available original document. 


\section{INTRODUCTION}

Modeling is an important tool in the design and evaluation of vehicles. Direct testing of vehicles is expensive, time consuming and difficult. While it is recognized that vehicle testing is always necessary, models can provide accurate estimates of vehicle performance at a reduced cost and effort. Modeling also provides a method for testing new concepts and ideas at early stages in the vehicle development process.

This report describes a vehicle evaluation code. This code has been developed to analyze electric and hybrid vehicles. Electric and hybrid vehicles are currently receiving great attention, due to concerns about pollution and energy efficiency. Electric vehicles are the best developed technology that can be used to meet the 1998 zero emission vehicle mandates imposed by the State of California, and hybrid vehicles offer the potential for very high energy efficiencies, long driving ranges, and low pollution (zero pollution for fuel cell hybrids).

Several electric and hybrid vehicle models exist in the literature. Interest in electric vehicles in the late 1970s and early 1980s resulted in many models (Chang, 1979; Unnewehr and Knoop, 1979; O'Connell et al., 1980; Dobner and Woods, 1982; DeWispelare, 1983; among others); and the current interest has resulted in the development of a new generation of vehicle codes. These include, among others, a code that applies to pure electric vehicles, focusing especially on battery simulation (Marr et al., 1991); a code to simulate stirling engine hybrids (Schreiber et al., 1992); and a code applicable to electric vehicles and rangeextender hybrids (Cole, 1993). The new models differ from the older models in the characteristics of the individual components being simulated, as well as in the vehicle configurations being analyzed, because progress in power electronics makes now possible not only more efficient components, but also more efficient configurations than those available in the past. All these models incorporate a wide range of degrees of detail and complexity. As with all models, increasing the accuracy results in an increased complexity of the model, as well as in an increased need for vehicle data.

The Hybrid Vehicle Evaluation Code (HVEC) described in this report has been developed to evaluate many of the vehicle configurations currently being considered for low emission and high energy efficiency vehicles. HVEC is capable of analyzing vehicles with different combinations of primary power supplies (engines, fuel cells), and energy storage devices (batteries, flywheels, ultracapacitors). 
HVEC applies only to electric vehicles and series hybrids in which the primary power supply and the storage system provide only electric power to the traction motor. No mechanical connection between primary power supply, storage, and traction motor is allowed. Due to this limitation, HVEC cannot be applied to simulate conventional vehicles. Figure 1 shows a schematic of the vehicle configuration that can be simulated with HVEC.

The following sections describe the evaluation code and the models used for the individual components.

\section{DESCRIPTION OF THE CODE}

As stated previously, HVEC applies only to electric and series hybrid vehicles. The vehicle configurations that can be analyzed with HVEC are listed in Table 1, along with a brief description of each. Table 1 includes some of the configurations that present the most interest for high efficiency and low pollution vehicles. These configurations also represent the most common combinations of primary power supplies and energy storage devices. Table 1 does not list separate configurations for ultracapacitors, because these are simulated in the same way as flywheels (although most likely with different parameters).

The code operates in batch mode, with all the information for the vehicle provided in a data file. The user starts by selecting a vehicle configuration from the list given in Table 1 . After this is done, the user selects the names for the vehicle data file and two result data files (a short, summary file; and a long, more detailed file). The user can select these files by either typing in a file name, or by selecting the default file names given by the code. A list of all the information required to describe a vehicle, taken from an example data file, is shown in Table 2, for an engine-flywheel hybrid (configuration 4).

HVEC starts by simulating a test drive of the vehicle over three driving cycles. The driving cycles are: a constant $88 \mathrm{~km} / \mathrm{h}$ ( $55 \mathrm{mph})$ drive, the EPA Federal Urban Driving Schedule, and the Highway Driving Schedule. The velocity-time relations for the urban and highway driving schedules are respectively shown in Figs. 2 and 3. For vehicle configurations 1,2 and 3 (limited range vehicles), each driving cycle is repeated until the vehicle energy or power is not enough to meet the requirements of the drive. For vehicle configurations 4,5 , 6,7 and 8 , the driving cycles are repeated until the vehicle travels a specified distance. This distance is chosen to be long enough to yield good average values over many cycles. 
No consideration is given to the possibility of having vehicles $4,5,6,7$ and 8 run out of fuel. It is assumed that they either have a fuel tank that is large enough to drive the specified distance, or that they can be refueled without delay. However, the test drive for vehicles $4,5,6,7$ and 8 can stop before reaching the specified length of the test drive if the primary power source (engine or fuel cell), or the energy storage system, is not powerful enough to meet the requirements of the driving schedule. HVEC requires all vehicles to precisely meet the velocity-time relations imposed by the driving cycles.

HVEC uses basic vehicle dynamics equations (Gillespie, 1992) to calculate the required motor power during vehicle operation. The user can specify vehicles with or without regenerative braking (except for fuel cell vehicles with no electrical storage capability, configuration 8 , for which the code assumes no regenerative braking). In hybrid vehicles, HVEC controls the energy flows in and out of the primary power supply, the storage system, and the motor, with strategies aimed at yielding maximum energy efficiency. In hybrid vehicles with an engine or a fuel cell, the engine or fuel cell initially operates at a fixed power to charge the storage system. When the storage is fully charged, the engine or fuel cell is turned off, and the storage provides all the energy for propulsion and for accessories. This process continues until the storage is discharged to some preset level. At this point, the engine or fuel cell is turned on to start a new cycle. Deep storage cycles are desirable to reduce the cycling frequency of the engine or fuel cell. However, the depth of discharge for batteries is usually limited to $80 \%$, to avoid battery damage. Flywheels and ultracapacitors are discharged until they have a small amount of energy, which may be necessary if a sudden acceleration (such as for passing) is required before the engine or fuel cell can start operating. While HVEC assumes that engines and fuel cells in hybrid vehicles usually operate at a fixed, normal power, HVEC also allows engines and fuel cells to work at a high power setting, which is used exclusively for long hill climbing, for which the storage system may not have enough energy to provide the desired performance. As the vehicle operates most of the time at normal power, the engine and generator, or fuel cell, are optimized for this condition, and the efficiency of the system may be lower at the high power setting.

At the end of each test drive, HVEC gives the results for distance travelled, energy consumption, gasoline-equivalent miles per gallon, and average efficiency of the motor for the driving cycle. After completing the three test drives, HVEC calculates the time for 0$96 \mathrm{~km} / \mathrm{h}$ acceleration, and hill climbing performance: range on a $5 \%$ and on a $30 \%$ hill for 
vehicles 1, 2, and 3; and continuous hill climbing slope at a $96 \mathrm{~km} / \mathrm{h}$ speed for vehicle configurations $4,5,6,7$ and 8 .

After completing all energy efficiency and performance analyses, HVEC calculates the weight and volume of the power train, which may include: storage system, engine, fuel cell, generator, motor and controller, and fuel tank, depending on which vehicle is specified. Weights and volumes are calculated from values and correlations given in the literature (DeLuchi, 1992; Allison, 1993); or from correlations derived from manufacturer's equipment catalogs.

HVEC bases the performance calculations on the overall vehicle weight input in the vehicle data file (see Table 2), and therefore, the power train component weights estimated by HVEC do not have any effect on the performance calculations. Power train component weights are calculated to help the user in verifying that they are compatible with the overall vehicle weight given in the vehicle data file. If the power train weight is too high or too low for the overall vehicle weight, the user can easily adjust the overall vehicle weight, or vary it within a range, to evaluate the effect of power train weight on vehicle performance. Previous models (DeWispelare, 1983) have used power train weights to calculate overall vehicle weight. While this may be useful in some instances, it is not done in HVEC due to the uncertainties involved in the process.

Finally, the code calculates vehicle pollutant generation. For electric and flywheel vehicles (configurations 1,2 , and 3 ), pollution is calculated by assuming that the electricity required to charge the battery or flywheel is generated at a natural gas power plant. For vehicles with an engine, the user can choose between a gasoline engine, a natural gas engine, or a hydrogen engine. Pollution figures for the gasoline engine assumed a generation of pollutants at a rate equal to the CARB LEV (California Air Resources Board Low Emission Vehicle) limits. For the natural gas engine, the code uses the CARB ULEV (Ultra Low Emission Vehicle) limits, which have been recently demonstrated (Cogan, 1993). For the hydrogen engine, HVEC uses the pollution rates given by Smith, 1993, for a hydrogen engine operating very lean. Fuel cells are assumed to be nonpolluting, except for $\mathrm{CO}_{2}$ production. For $\mathrm{CO}_{2}$ calculations, hydrogen is assumed as being generated by steam reforming of natural gas at a $67 \%$ efficiency. If the hydrogen is obtained from a renewable source, $\mathrm{CO}_{2}$ production is equal to zero. 
HVEC allows the user to specify if any of three additional result data files should be generated. These files include information on the driving cycles, on the storage system, and on the maximum acceleration test, respectively. HVEC also has an option which allows running for multiple values of a single variable. This option is very useful in parametric analyses, optimization, or for vehicle synthesis, where the performance specifications are given, and the goal is to find vehicle characteristics that are compatible with these specifications. This option allows rapid assessment of fuel economy sensitivity to design variables.

\section{VEHICLE COMPONENT SIMULATION}

This section describes the procedure used to simulate the main vehicle components.

1) Electric Motor and Controller: The efficiency of the electric motor and controller is calculated by using performance maps provided by manufacturers. The performance maps are specified in data files as tables of efficiency values as a function of torque and RPM. HVEC then uses Lagrangian interpolation to obtain the efficiency for any combination of torque and RPM. HVEC includes data files for two induction AC motors, a synchronous $\mathrm{AC}$ motor, and a DC motor. The user has the choice of selecting one of these motors, or generate and use a data file for a different motor.

The electric motor simulation assumes that the performance maps are scalable in terms of the maximum torque and speed, so that a single motor map can be used for a family of motors with the same characteristics and different sizes. According to Unnewehr and Knoop, 1979, this is a good assumption, if the difference in sizes is not very large.

2) Transmission: The transmission is simulated by specifying the vehicle speeds at which an upshift or a downshift occurs, as well as the reduction ratios for each of the gears. HVEC simulates a 3 speed transmission, but the same transmission model can be used to simulate two speed, or fixed ratio transmissions if the speed for shifting into the higher gears is set very high, so that the vehicle never shifts into these gears. The model assumes a constant transmission efficiency, which is also specified by the user.

3) Engine and Generator: As previously discussed, engines used in the present model operate at two fixed conditions, in an on-off mode. The two conditions are: normal pọwer, used for regular city and highway driving; and high power, used for long hill 
climbs. Therefore, the engine can be completely characterized by specifying the engine efficiency and power at normal and high power conditions. Engine transients are assumed to last a very short time and are therefore neglected (For hydrocarbon fuels, anticipation of engine startup by the controller would allow electrical preheat of the catalyst to achieve steady-state emissions).

The generator is also specified by two efficiency values, one at the normal power conditions, and the other at the high power conditions, since generator efficiency is also a function of torque and RPM. Operating the engine and generator at fixed conditions makes it possible to optimize the system at the normal power conditions, which is the most usual operating point. The system efficiency is then higher than the efficiency of an engine and generator that have to operate over a wide range of conditions.

4) Fuel Cell: In hybrid vehicles (configurations 6 and 7), fuel cells are assumed to operate at two fixed power settings, in the same mode of operation used for constant speed engine hybrids. Therefore, fuel cells in hybrid vehicles (configurations 6 and 7) are also completely characterized by the efficiency and power at the high power mode and at the normal power mode. In pure fuel cell vehicles (configuration 8 ), fuel cells directly provide all the energy to drive the traction motor. This configuration is evaluated by using fuel cell efficiency data as a function of generated power. Fuel cell information is stored in a data file. HVEC includes data for a proton exchange membrane fuel cell (Allison, 1993). The user can choose this data file, or generate and use a data file that is appropriate for a particular application.

5) Flywheel or Ultracapacitor: Flywheels or ultracapacitors are defined by specifying the energy storage capacity, the energy storage density (per unit mass of the system), the maximum specific power (maximum power divided by total system mass), and the turnaround efficiency, which is assumed constant. HVEC keeps an inventory of the energy stored in the system, and controls the operation of the engine or fuel cell based on this value.

6) Batteries: Batteries are, among all the vehicle components analyzed by HVEC, the component that presents the maximum difficulty to simulate with a good degree of accuracy. Battery performance is a function of many parameters, such as materials and construction methods, battery age, battery discharge rate, battery discharge history, and temperature. All these factors affect significantly the battery performance. 
HVEC uses the battery descriptions and routines previously used by Marr et al., 1991, for an electric vehicle simulation model. This model uses basic equations for the electric circuits, along with experimental correlations for cell internal resistance and zero load voltage as a function of battery depth of discharge, to evaluate the energy and power available. Battery temperature effects are not included in the model, but can be incorporated if experimental data are available.

Battery information is stored in data files. HVEC includes data files for the following types of batteries:

- Tubular lead-acid battery

- Nickel-Iron battery

- Sodium-Sulphur battery

The user can choose any of these data files, or generate a data file that is appropriate for a particular application, provided that the required experimental results are available. It should be recognized that this is a difficult procedure, because a battery model is usually appropriate only for the specific type of battery for which the experimental results were obtained.

When battery data are limited, and high accuracy is not required, the flywheel model can be used to simulate a battery. The flywheel model only requires information on specific energy, specific power, and turnaround efficiency, which are available for most battery types. This approach has been used by some researchers in the past (Schreiber et al., 1992), and can be used to obtain initial estimates to vehicle range, energy consumption, and performance.

\section{APPLICATION OF THE CODE}

HVEC is now applied to the analysis of a five passenger, engine-flywheel hybrid vehicle which utilizes a hydrogen internal combustion engine. This vehicle is described by Smith and Aceves, 1995, and is being developed as a general purpose, long range vehicle, which will pollute less than an electric vehicle, taking power plant pollution into account. This vehicle may also be capable of a fuel economy of 80 miles per gallon, which has been set as a goal by the Partnership for the New Generation of Vehicles (PNGV). The vehicle specifications are given in Table 2. While the values listed in the table are estimates, the 
values chosen are believed to be obtainable with current technology. However, it is recognized that key vehicle components (engine and flywheel) are still under development, and therefore it is possible that the final performance figures may be different than the estimated values listed. It should also be pointed out that at the high mileage efficiencies of such vehicles, small changes in accessory loads or wind loads can have significant effects on energy equivalent mileage.

Table 3 lists the results obtained for the vehicle. All information is listed in metric units, except for energy consumption (in $\mathrm{Wh} / \mathrm{mile}$ ), fuel economy (in $\mathrm{mpg}$ ), and pollution (in grams/mile) due to the general use of these units. The calculations assume a lower heating value for gasoline equal to $1.25 \times 10^{8} \mathrm{~J} / \mathrm{gal}$. As can be seen, the model predicts a very high combined fuel economy ( $86.9 \mathrm{mpg}, 55 \%$ urban, $45 \%$ highway), and very low emissions. Fuel economy is lower for the urban cycle than for the highway cycle, mainly due to the accessory load (1000 W total; $500 \mathrm{~W}$ for air conditioning and $500 \mathrm{~W}$ for other accessories), which has to be provided during vehicle operation. Since a vehicle in the urban driving cycle takes longer to complete the specified distance, more energy is necessary to satisfy the accessory load in this cycle. The results also show a power train weight and volume which are reasonable compared to the overall vehicle weight (1136 kg empty weight, see Table 2). The values for the fuel tank weight and volume listed in Table 3 correspond to a cryogenic liquid hydrogen storage.

The code has also been used for parametric studies of the vehicle. Parametric studies are important because, as previously discussed, some of the vehicle data are subject to change. It is also desirable to know how sensitive the fuel economy of the vehicle is to variations in the different parameters. This information allows the vehicle developer to spend a greater effort on improving the parameters that are the most important for obtaining a high fuel economy.

Figures 4-7 show the results of the parametric analyses. Figure 4 is a fuel efficiency map for the hydrogen hybrid vehicle, with contour lines that indicate gasoline equivalent miles per gallon, as a function of vehicle mass and vehicle $C_{d}{ }^{*} A$, where $C_{d}$ is the drag coefficient, and $A$ is the frontal area of the vehicle. The product $C_{d}{ }^{*} A$ determines the aerodynamic drag on the vehicle. The figure shows a substantial separation between constant fuel economy lines, which indicates that fuel economy is fairly insensitive to vehicle mass and aerodynamic drag. The figure also shows three operating conditions, each for a hydrogen storage system being currently evaluated. The point labeled "liquid" is 
for liquid hydrogen storage. This vehicle is described in Tables 2 and 3. The label "comp" identifies the operating condition for a vehicle with a $61800 \mathrm{kPa}(9000 \mathrm{psi})$ compressed hydrogen storage. The point labeled "MgH" identifies a vehicle operating with advanced magnesium hydride storage. As the figure indicates, all three vehicles surpass the $80 \mathrm{mpg}$ PNGV fuel efficiency goal.

Figure 5 also shows a fuel economy map for the hydrogen hybrid vehicle, with fuel economy as a function of flywheel efficiency and engine-generator efficiency. The figure shows that both of these parameters have a strong effect on the fuel economy of the vehicle. The region in which the fuel economy exceeds $80 \mathrm{mpg}$ occupies only the upper right corner of the figure, indicating that a combination of high flywheel efficiency and high engine-generator efficiency is necessary to achieve the PNGV goal. Reaching the flywheel and engine-generator efficiency values indicated in this figure is probably the biggest challenge in designing a vehicle that meets the PNGV goal. The figure also shows two operating points, respectively for vehicles with a hydrogen engine, and with a compressed natural gas $(\mathrm{CNG})$ engine. Vehicles with a gasoline engine have an estimated enginegenerator efficiency slightly lower than $30 \%$, which is too low to appear in the figure. As can be seen, CNG and gasoline flywheel hybrids cannot reach the $80 \mathrm{mpg}$ mark.

Flywheel energy storage capacity and power are also important parameters for vehicle design. It is especially important to know the minimum flywheel energy storage capacity and power that results in satisfactory vehicle operation. Figures 6 and 7 show the results of a parametric analysis, in which the flywheel energy storage capacity is varied between $0.25 \mathrm{kWh}$ and $2 \mathrm{kWh}$. The analysis assumes a ratio of flywheel energy capacity to peak power of 0.01 hours, estimated from the values given in a recent publication (Smith, 1993).

Reducing the flywheel energy capacity results in a reduction of the time length of the engine on-cycles. As the flywheel energy storage decreases, it is charged and discharged in less time. Figure 6 shows average engine on-time and off-time, for the urban and highway cycles, for the hydrogen hybrid vehicle. The linearity of the curves (except for some variations due to the irregularities in the driving cycle) indicates that the engine duty cycle (fraction of the total time in which the engine is on) remains constant in the whole range, approximately equal to 0.13 for the urban cycle, and 0.26 for the urban cycle. For small flywheel capacities, the average engine on-time drops to under 1 minute, and it is possible that engine design considerations, or engine cycling losses (not considered in the current 
analysis) may set a lower limit to the flywheel energy capacity. Otherwise, power requirements set a lower limit to flywheel output at about $35 \mathrm{~kW}$ for both cycles (a slightly higher minimum power is required for the urban cycle than for the highway cycle, as shown in the figure).

Figure 7 shows fuel economy and required time to reach $96 \mathrm{~km} / \mathrm{h}(60 \mathrm{mph})$, as a function of flywheel energy and power capacity, for the hydrogen hybrid vehicle. Fuel economy is not affected by flywheel storage capacity, because HVEC neglects transient engine losses. Transient losses may, in some engines, cause a decrease in fuel economy for short cycles (i.e., at low flywheel capacities). The time for maximum effort acceleration from 0 to 96 $\mathrm{km} / \mathrm{h}$ drops rapidly from $30 \mathrm{~s}$ to $8 \mathrm{~s}$ as the flywheel power increases from $25 \mathrm{~kW}$ to 100 $\mathrm{kW}$. Further increases in flywheel power do not have any effect on the time for maximum acceleration, because, for high flywheel power, maximum acceleration is limited by maximum motor power output.

\section{CODE VALIDATION}

Validation of vehicle simulation models is difficult due to the great number of variables that affect vehicle performance. A rigorous code validation requires a statistical analysis, in which the code results are compared to the average vehicle performance obtained over many test drives, to reduce the effect of random variations in vehicle parameters (Waters, 1972).

HVEC has not been validated according to the criterion established in the previous paragraph. However, HVEC has been applied to simulate the performance of current electric vehicle prototypes for which the required vehicle and performance parameters are known. The results of the analysis indicate an agreement within $10 \%$ between the experimental and calculated values, for fuel economy as well as for time for maximum effort acceleration. While not a rigorous validation, this agreement is considered satisfactory, and appears to indicate that code results are a good indication of vehicle performance. 


\section{CONCLUSIONS}

This report describes a hybrid vehicle simulation model, which can be applied to many of the vehicle configurations currently being considered for low pollution and high fuel economy. The simulation model is first described in detail, and then it is applied to the analysis of a hydrogen hybrid vehicle. The results indicate that the model is useful for

predicting vehicle fuel economy and performance, and is expected to be a valuable tool in vehicle development. 


\section{REFERENCES}

1) Allison Gas Turbine Division, GM Corp., 1993, "Research and Development of Proton Exchange Membrane (PEM) Fuel Cell System for Transportation Applications, Initial Conceptual Design Report," Report EDR 16194, Prepared for the Office of Transportation Technologies, Department of Energy.

2) Chang, M.C., 1979, "Computer Simulation of an Advanced Hybrid Electric Power Vehicle," SAE Transactions, Vol. 87, Section 1, pp. 890-904.

3) Cole, G.H., 1993, "SIMPLEV: A Simple Electric Vehicle Simulation Program Version 2.0," Idaho National Engineering Laboratory Report DOE/ID-10293-2.

4) DeLuchi, M., 1992, "Hydrogen Fuel Cell Vehicles," Institute of Transportation Studies Report UCD-ITS-RR-92-14, University of California, Davis, CA.

5) DeWispelare, A.R., 1983, "Electric Vehicle Modeling and Simulation," Technical Report AU-AFIT-EN-TR-83-4, School of Engineering, Air Force Institute of Technology, Wright-Patterson Air Force Base.

6) Dobner, D.J., and Woods, E.J., 1982, "An Electric Vehicle Dynamic Simulation," SAE Paper 820779, Presented at the Passenger Car Meeting, Troy, MI, June 1982.

7) Gillespie, T.D., 1992, "Fundamentals of Vehicle Dynamics," Society of Automotive Engineers, Warrendale, PA.

8) Marr, W.W., Walsh, W.J., and Symons, P.C., 1991, "User's Guide to DIANE Version 2.1: A Microcomputer Software Package for Modeling Battery Performance in Electric Vehicle Applications," Argonne National Laboratory Report ANL/ESD--8, DE91 006071.

9) Cogan, R.J., Editor, 1993, "Chrysler Expands NGV Lineup," Green Car Journal, Vol. 2, p. 38.

10) O'Connell, L.G., Anderson, C.J., Behrin, E., Cliff, W., Crisp, R., Forsberg, H.C., Hudson, C.L., Payne, J.S., Renner, R., Schrot, M.D., Strickland, G., Schwartz, M., Walsh, W.J., 1980, "Energy Storage Systems For Automobile Propulsion, Final Report," Lawrence-Livermore National Laboratory Report UCRL53053-80.

11) Schreiber, J.G., Shaltens, R.K., and Beremand, D.G., 1992, "Electric and Hybrid Electric Vehicle Study Utilizing a Time-Stepping Simulation," Proceedings of the IECEC Conference, Vol. 3, pp. 159-165.

12) Smith, J.R., 1993, "The Hydrogen Hybrid Option," Proceedings of the Workshop on Advanced Components for Electric and Hybrid Electric Vehicles, Gaithersburg, MD. NIST Special Publication 860. 
13) Smith, J.R., and Aceves, S.M., 1995, "A Hydrogen-Hybrid Concept Automobile," Submitted to the 3rd Annual ESD Environmental Vehicles Conference and Exposition, Dearborn, MI, January 23-25, 1995.

14) Unnewehr, L.E., and Knoop, C.W., 1979, "Electrical Component Modeling and Sizing for EV Simulation," SAE Transactions, Vol. 87, Section 1, pp. 877-889.

15) Waters, W.C., 1972, "General Purpose Automotive Vehicle Performance and Economy Simulator," SAE Paper 720043. 


\section{FIGURE CAPTIONS}

1) Schematic of the vehicle configuration that can be simulated with HVEC. Solid arrows indicate the allowable directions for electrical energy transfer, and dotted arrows indicate mechanical energy transfer. Primary power supplies are engines or fuel cells. Storage systems are flywheels, ultracapacitors or batteries.

2) Velocity as a function of time for the EPA Urban Driving Cycle.

3) Velocity as a function of time for the EPA Highway Driving cycle.

4) Fuel economy map for the hydrogen hybrid vehicle. The contour lines indicate gasoline equivalent miles per gallon, as a function of vehicle mass and vehicle $C_{d}{ }^{*} A$, where $C_{d}$ is the drag coefficient, and $A$ is the frontal area of the vehicle. The product $\mathrm{C}_{\mathrm{d}}{ }^{*} \mathrm{~A}$ determines the vehicle aerodynamic drag. The stars indicate the estimated operating points for vehicles with liquid hydrogen storage, $61800 \mathrm{kPa}$ (9000 psi) compressed hydrogen storage, and magnesium hydride storage.

5) Fuel economy map for the hydrogen hybrid vehicle. The contour lines indicate gasoline equivalent miles per gallon, as a function of engine-generator combined efficiency and flywheel turnaround efficiency. The stars indicate the estimated operating points for vehicles with a hydrogen and a compressed natural gas internal combustion engine.

6) Average engine on-time and off-time, for the urban and highway driving cycles, as a function of flywheel energy storage capacity, for the hydrogen hybrid vehicle.

7) Vehicle fuel economy and required time to reach $96 \mathrm{~km} / \mathrm{h}$, as a function of flywheel energy and power capacity, for the hydrogen hybrid vehicle. 

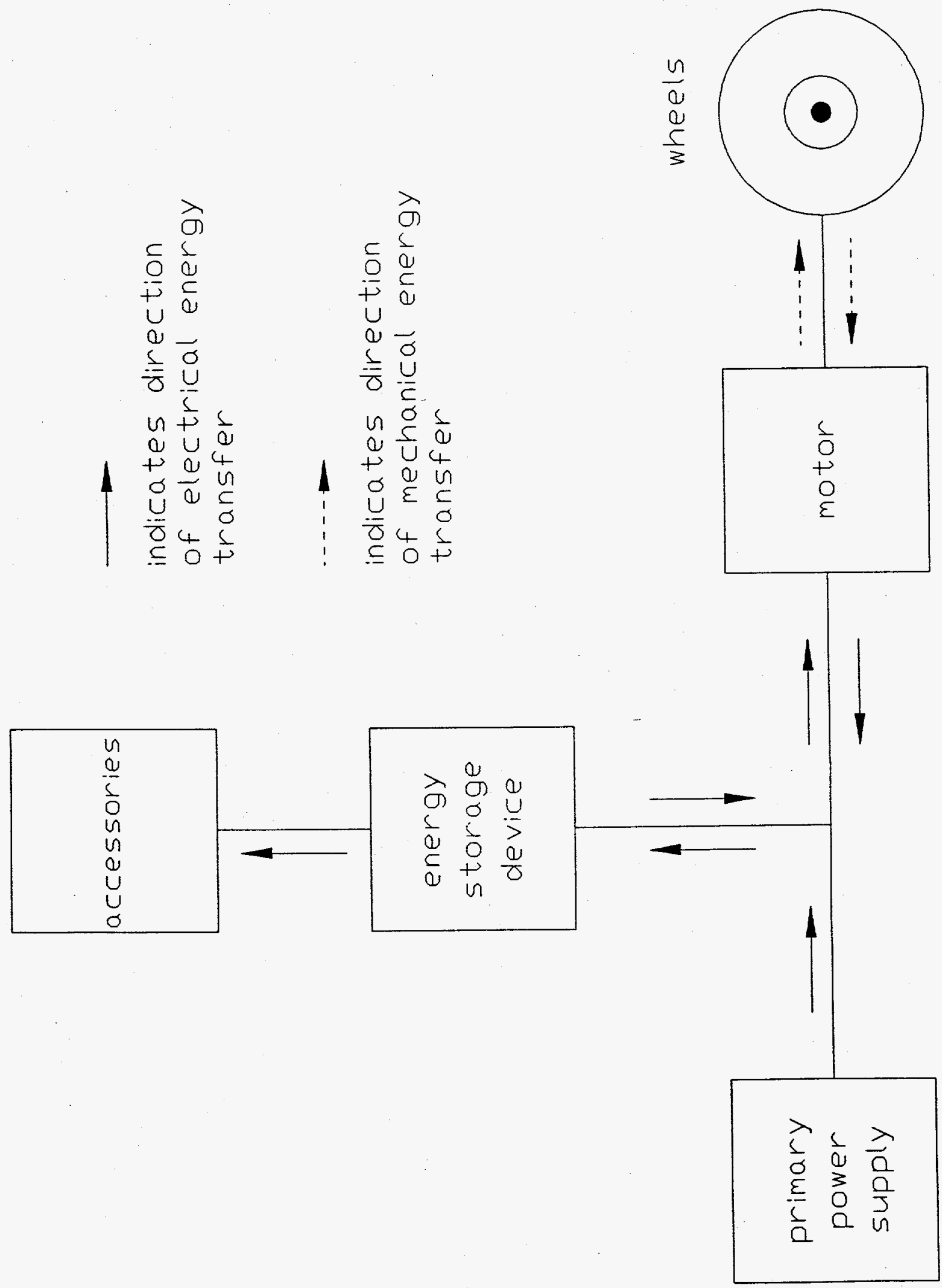


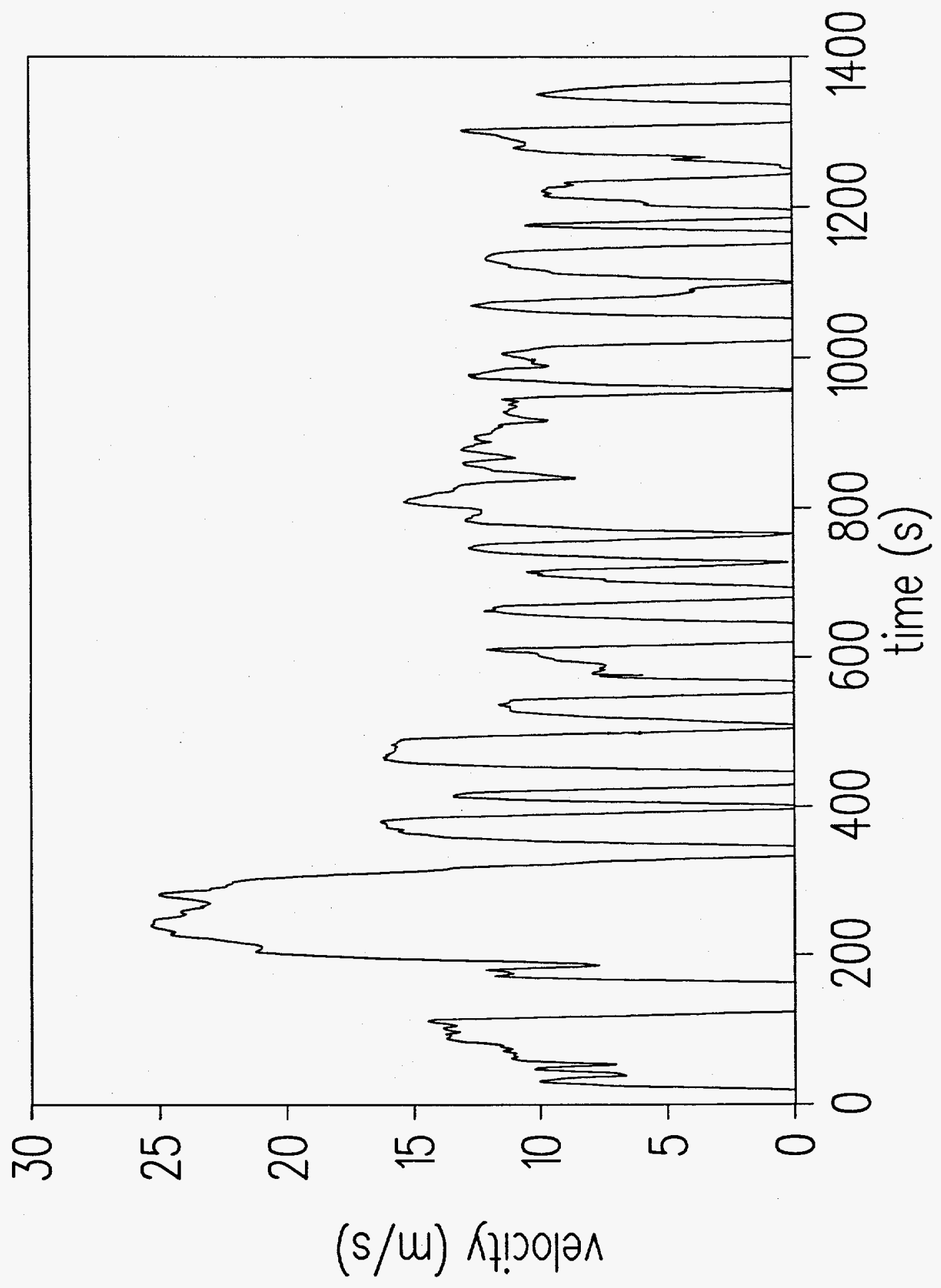

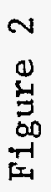




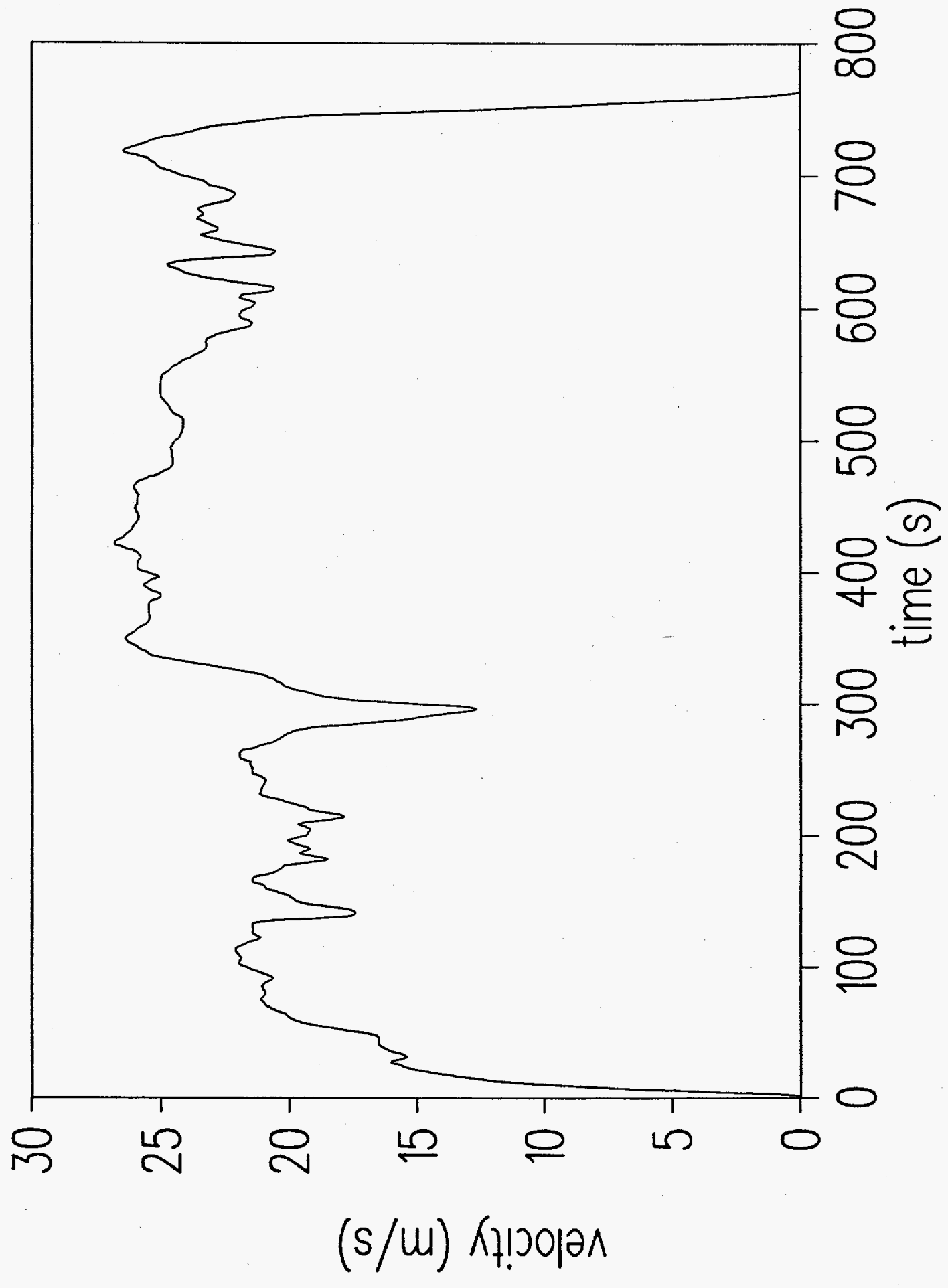




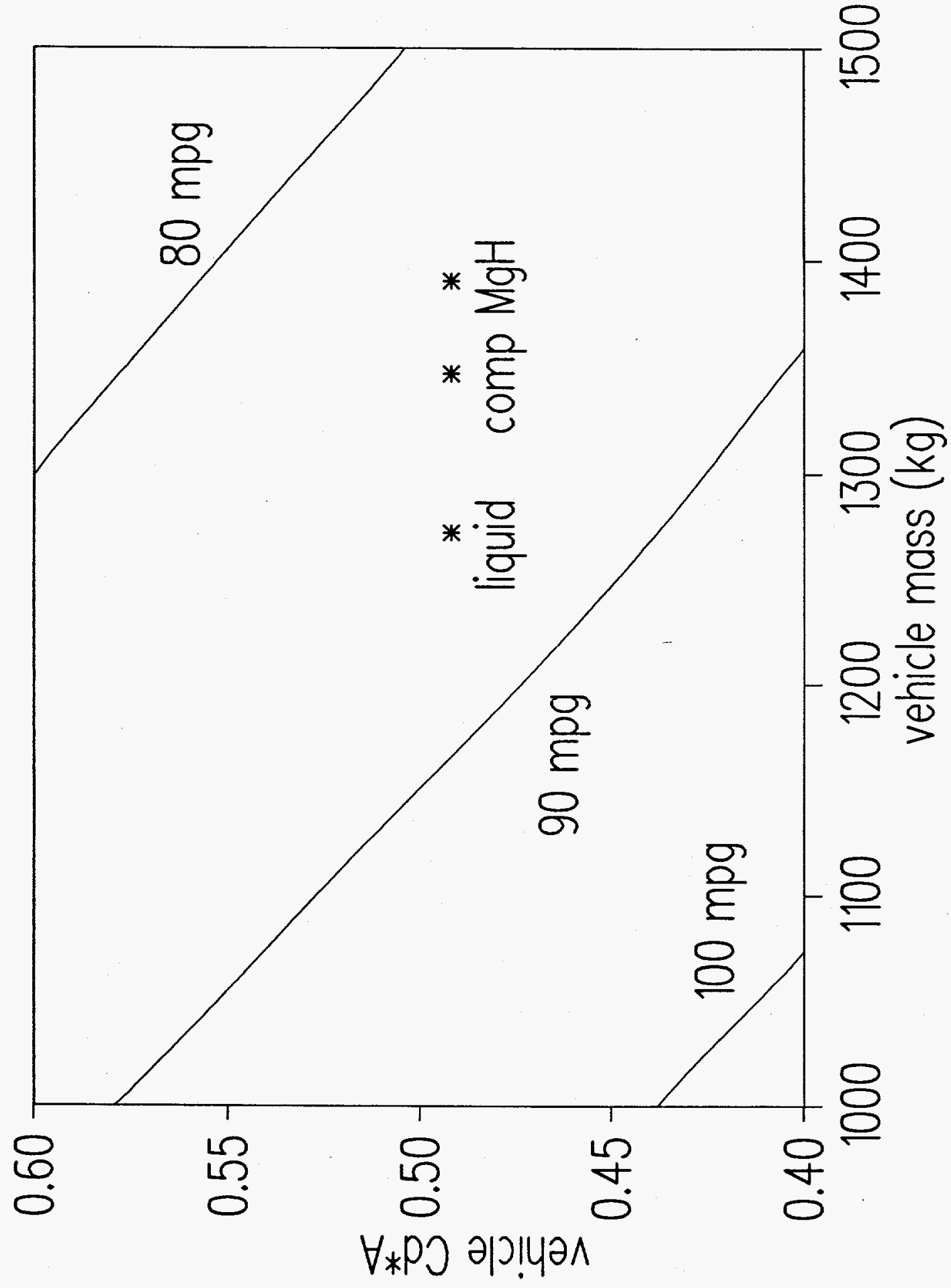




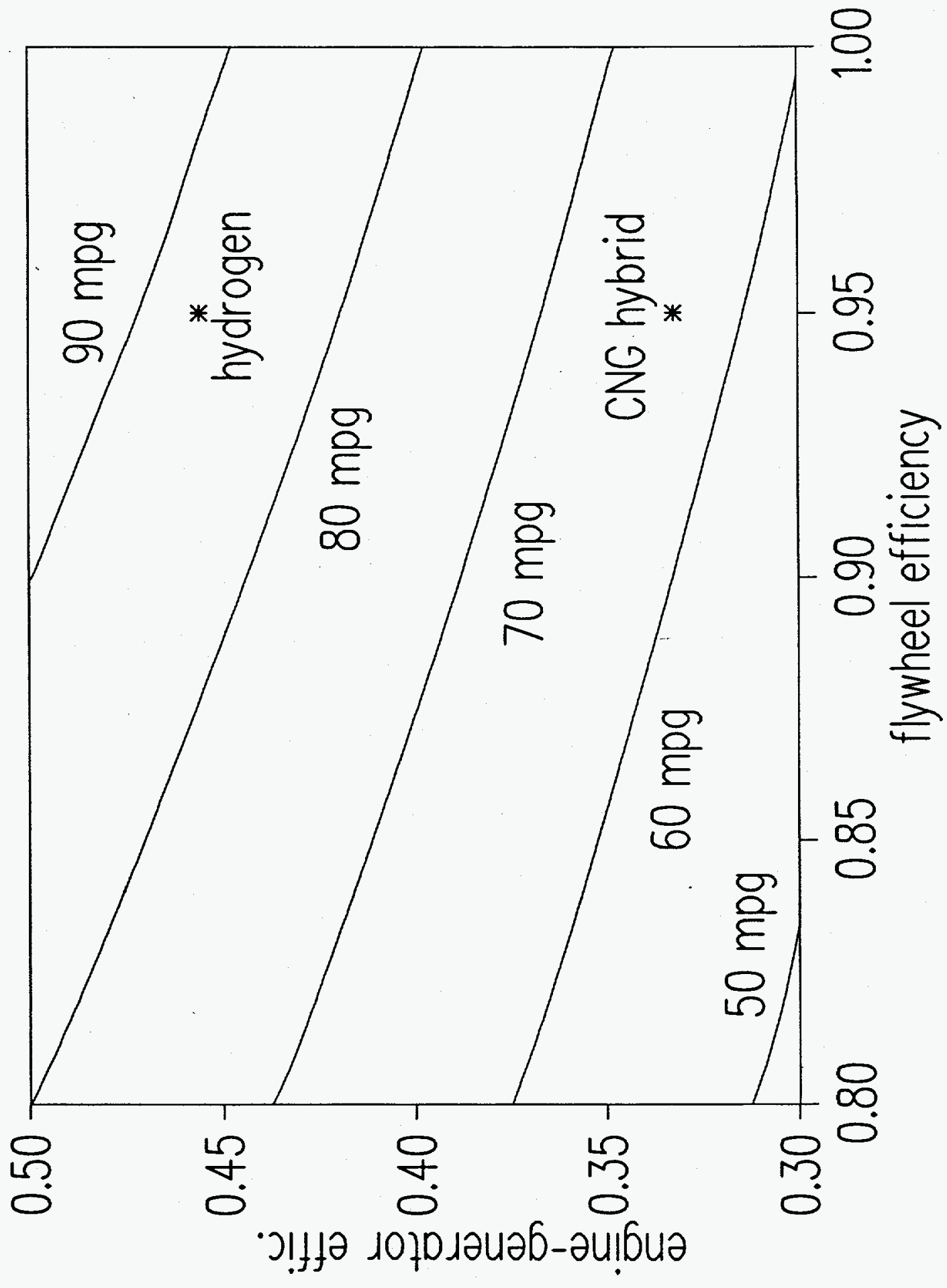




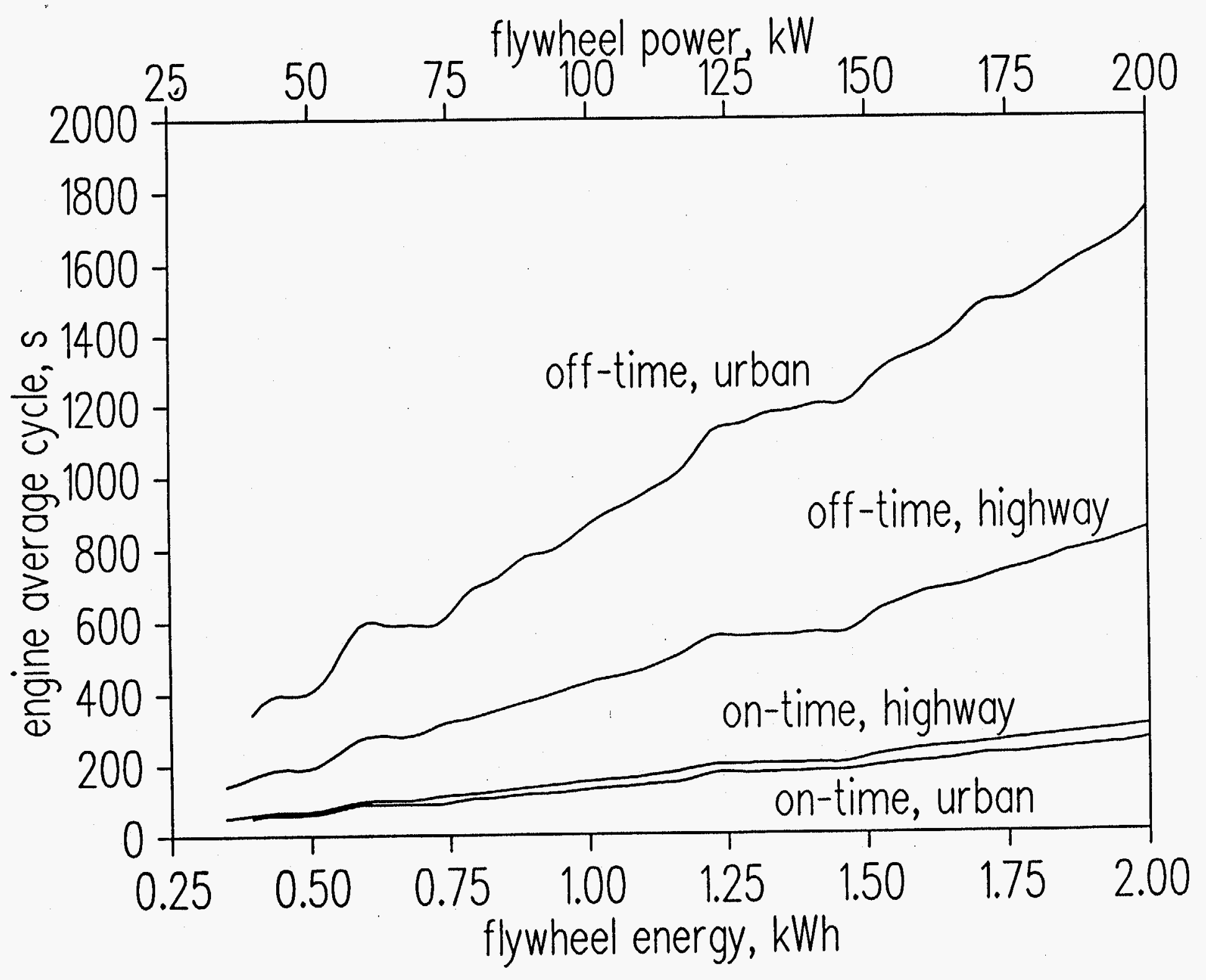




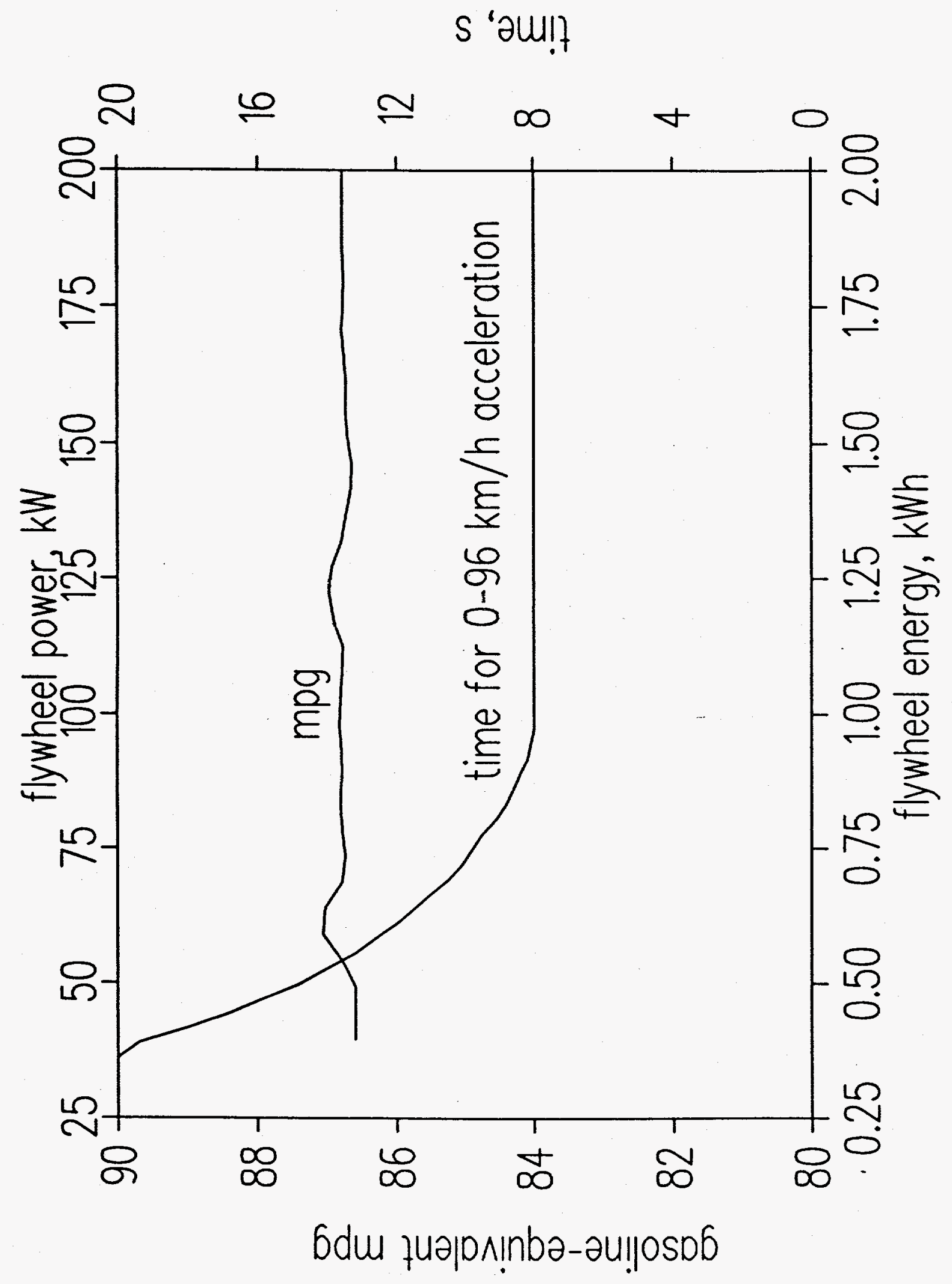


Table 1. List of vehicle configurations that can be analyzed with HVEC, including a brief description of each. Ultracapacitors are simulated in the same way as flywheels, and therefore the list does not include separate configurations for ultracapacitors.

1. Electric vehicle. Conventional battery-powered electric vehicle.

2. Flywheel vehicle. Electric vehicle which uses a flywheel instead of a battery for energy storage.

3. Battery-flywheel hybrid. This vehicle uses a flywheel for leveling the battery load and for regenerative braking.

4. Engine-flywheel hybrid. This vehicle uses an engine operating at a fixed power, in an on-off mode, to keep the flywheel at an appropriate state of charge. The flywheel provides the power peaks, stores the engine energy not required for traction, and provides all the traction energy when the engine is off.

5. Engine-battery hybrid. This vehicle operates in exactly the same way as the engineflywheel hybrid, with the flywheel replaced by a battery for energy storage.

6. Fuel cell-flywheel hybrid. The operation of this vehicle is also the same as the operation of the engine-flywheel hybrid, with the fuel cell providing a constant power, in an on-off mode.

7. Fuel cell-battery hybrid. In this vehicle, the fuel cell also operates at a constant power in an on-off mode. Energy storage is provided by batteries.

8. Fuel cell vehicle. In this vehicle, the fuel cell directly drives the motor. The vehicle has no energy storage device, other than the fuel tank, and therefore regenerative braking is not an option. 
Table 2. Information required for the vehicle specification data file for vehicle configuration 4 (engine-flywheel hybrid), for a hydrogen hybrid vehicle with an optimized engine.

\section{Title of run}

\section{LLNL Hydrogen Hybrid Vehicle}

Enter type of electric motor

1. DC motor

2. AC synchronous motor

3. AC induction motor

4. AC induction motor

5. User-Defined motor

Is there regenerative braking? $1=y e s, 0=$ no

Vehicle characteristics

1. overall vehicle weight in $\mathrm{kg}$ (empty weight $+136 \mathrm{~kg}$ )

2. frontal area in $\mathrm{m} 2$

3. aerodynamic drag coefficient

0.24

4. coefficient of rolling friction

0.007

5. 2nd coefficient of rolling friction in $\mathrm{s} / \mathrm{m}$

Motor characteristics

11. motor maximum continuous torque in $\mathrm{N}-\mathrm{m}$

12. motor maximum RPM

Transmission characteristics

21. transmission efficiency

0.92

22. velocity for changing to 2 nd gear, $\mathrm{m} / \mathrm{s}$

23. velocity for changing to $3 \mathrm{rd}$ gear, $\mathrm{m} / \mathrm{s}$

80.5

24. 1st gear reduction ratio, $\mathrm{RPM} /(\mathrm{m} / \mathrm{s})$

410.0

25. 2nd gear reduction ratio, $R P M /(\mathrm{m} / \mathrm{s})$

26. 3rd gear reduction ratio, RPM $/(\mathrm{m} / \mathrm{s})$

200.0

Moment of inertia contributions

31. tire radius, $\mathrm{m}$

32. moment of inertia for 4 tires and axles, $\mathrm{kg} \mathrm{m}^{2}$

33. moment of inertia for motor and transmission, $\mathrm{kg} \mathrm{m}^{2}$

0.06

Energy storage

42. flywheel storage capacity, $J$

$7.2 \mathrm{E} 6$

43. flywheel specific energy storage, $\mathrm{J} / \mathrm{kg}$

44. flywheel maximum specific power, W/kg

$1.8 \mathrm{E} 5$

45. flywheel turnaround efficiency (output/input) 
Table 2. Cont.

Engine characteristics

Enter a number for engine type

1. Gasoline engine

2. Natural gas engine

3. Hydrogen engine

51. Engine power at peak efficiency in $W$

52. peak engine efficiency fraction

53. peak generator efficiency fraction

54. maximum continuous engine power in $\mathrm{W}$ (for hills)

55. engine efficiency fraction at maximum power

56. generator efficiency at maximum engine power

57. length of test drive, $m$

Accessories

Air Conditioning load is $10 \%$ of steady-state load at $50 \mathrm{mph}$

Do you want air conditioning? ( $1=y e s, 0=$ no)

61. additional accessory load

62. energy transfer efficiency between flywl and access

File control

Do you want a file (POWER.DAT) with drive power results?

(1=yes, $0=$ no)

Do you want a file (FLYWHEEL.DAT) with flywheel results?

( $1=$ yes, $0=$ no)

Do you want a file (ACCELRTN.DAT) with 0-60 $\mathrm{mph}$ accel data?

(1=yes, $0=$ no)

How many cycles for each schedule do you want in the files?

Parametric studies

Do you want to do a parametric study? $(1=$ yes, $0=$ no)

Enter variable number that is to be varied within a range

Enter minimum value of range

Enter maximum value of range 
Table 3. Results obtained for the hydrogen hybrid vehicle defined in Table 2.

a) Energy information for each driving cycle

Number of cycles

Total time, s

Distance travelled, $\mathrm{m}$

Consumed energy, J

W-hr/mile

Gasoline equivalent mpg

Motor avg cycle effic

Avg cycle eff regen br

\begin{tabular}{rrr}
$88 \mathrm{~km} / \mathrm{h}$ & \multicolumn{1}{c}{ Urban } & Highway \\
$(55 \mathrm{mph})$ & & 32 \\
& 43 & 24019 \\
20869 & 58183 & 517000 \\
513100 & 509900 & $4.13 \times 10^{8}$ \\
$4.12 \times 10^{8}$ & $4.96 \times 10^{8}$ & 357 \\
359 & 434 & 97.2 \\
96.8 & 79.9 & 0.897 \\
0.897 & 0.850 & 0.881
\end{tabular}

Combined gasoline equivalent $\mathrm{mpg}$

86.9

b) Performance characteristics

Time to reach $60 \mathrm{mph}, \mathrm{s}$

Distance travelled in $10 \mathrm{~s}, \mathrm{~m}$

$96 \mathrm{~km} / \mathrm{h}$ climbing slope in percent

8.0

191

5.4

c) Weights and volumes for power train

Component

Motor

Controller

Transmission

Flywheel

Engine

Generator

Fuel tank

Total weight and volume

$\begin{array}{cc}\text { Weight,kg } & \text { Vol.,liters } \\ 34 & 11 \\ 20 & 20 \\ 11 & 4 \\ 40 & 44 \\ 119 & 130 \\ 49 & 16 \\ 26 & 80 \\ 299 & 305\end{array}$

d) Pollutant generation in $\mathrm{g} /$ mile

LEV and ULEV values added for comparison

Vehicle

LEV

ULEV

$\mathrm{CO}_{2}$ :

$\mathrm{HC}$ :

116

$\mathrm{CO}$ :

$5.00 \times 10^{-3}$

$\mathrm{NO}_{\mathrm{X}}$ :

$5.00 \times 10^{-3}$

$1.24 \times 10^{-2}$

$7.50 \times 10^{-2}$

$4.00 \times 10^{-2}$

3.40

1.70

$2.00 \times 10^{-1}$

$2.00 \times 10^{-1}$ 